\title{
Assessment of community knowledge, attitude, and stigma of Buruli ulcer disease in Southern Nigeria
}

\begin{abstract}
Charles Chukwunalu Nwafor ${ }^{1}$, Anthony Meka ${ }^{1}$, Joseph Ngozi Chukwu ${ }^{1}$, Ngozi Ekeke ${ }^{1}$, Chukwuka Alphonsus ${ }^{1}$, Obinna Mbah ${ }^{1}$, Nelson Okechukwu Madichie ${ }^{2}$, Ufuoma Aduh ${ }^{3}$, Matthew Ogbeifo ${ }^{3}$, Bola Olubakin IseOluwa-Adelokiki ${ }^{4}$, Joseph Ezebunafor Edochie ${ }^{5}$, Joseph Ushaka ${ }^{6}$, Kingsley Nnanna Ukwaja ${ }^{7}$
\end{abstract}

1. Medical Department, German Leprosy and Tuberculosis Relief Association, Enugu State, Nigeria.

2. St Leo Hospital Enugu, Enugu State, Nigeria.

3. Delta State Tuberculosis, Leprosy and Buruli Ulcer Control Programme, Delta State, Nigeria.

4. Ogun State Tuberculosis, Leprosy and Buruli Ulcer Control Programme, Ogun State, Nigeria.

5. Anambra State Tuberculosis, Leprosy and Buruli Ulcer Control Programme, Anambra State, Nigeria.

6. Cross River State Tuberculosis, Leprosy and Buruli Ulcer Control Programme, Cross River State, Nigeria.

7. Department of Medicine, Federal Teaching Hospital Abakaliki, Ebonyi State, Nigeria.

\begin{abstract}
Background: Poor knowledge can influence timely care-seeking among persons with Buruli ulcer disease (BUD).

Objectives: To assess community knowledge, attitude and stigma towards persons with BUD in endemic settings of Southern Nigeria.

Methods: This was a cross-sectional survey conducted among adult community members in four States of Southern Nigeria. A semi-structured interviewer-administered questionnaire was administered to all participants.

Results: Of 491 adults who completed the survey, 315 (64.2\%) belonged to the $\leq 40$ years age group, $257(52.3 \%)$ were males and $415(84.5 \%)$ had some formal education. The overall mean (SD) knowledge score was 5.5 \pm 2.3 (maximum 10). Only 172 (35.0\%) of the participants had a good knowledge of BUD. A total of $327(66.6 \%)$ considered BUD as a very serious illness. Also, there was a high-level of stigma against BUD patients; $372(75.8 \%)$ of the participants felt compassion for and desire to help them, $77(15.7 \%)$ felt compassion but tended to stay away from them, and $53(10.8 \%)$ feared them because they may infect them with the disease. Having a formal education and ethnicity were independent predictors of good knowledge of BUD.

Conclusion: There is poor community knowledge of BUD in endemic settings of Southern Nigeria which influenced the attitude and perceptions of community members towards persons with BUD

Keywords: Mycobacterium ulcerans disease, knowledge, perceptions, practices.

DOI: https://dx.doi.org/10.4314/ahs.v19i2.34

Cite as: Nwafor CC, Meka A, Chukwu JN, Ekeke N, Alphonsus C, Mbab O, Madichie NO, Adub U, Ogbeifo M, IseOluwa-Adelokiki BO, Edocbie JE, Ushaka J, Ukwaja KN. Assessment of community knowledge, attitude, and stigma of Buruli ulcer disease in Southern Nigeria. Afri Health Sci.2019;19(2): 2100-2111. https:/ / dx.doi.org/10.4314/abs.v19i2.34
\end{abstract}

\section{Background}

Buruli ulcer disease (BUD) is a skin disease caused by $M y$ cobacterium ulcerans-a bacterium related to those that cause tuberculosis and leprosy ${ }^{1-3}$. The exact mode of the disease transmission to humans is still not clear ${ }^{1}$. The main risk

\section{Corresponding author:}

Kingsley Nnanna Ukwaja,

Department of Medicine,

Federal Teaching Hospital Abakaliki,

Ebonyi State, Nigeria

Email: ukwajakingsley@yahoo.co.uk factors of $M$. ulcerans infection is contact with swampy areas and swimming in slow-flowing rivers or streams ${ }^{2-3}$. BUD occurs mainly in tropical and subtropical regions except in Australia, China and Japan ${ }^{1}$. Most cases of BUD reported from Africa annually come mainly from West and Central Africa, including Benin, Cameroon, Côte d'Ivoire, Democratic Republic of the Congo and Gha$\mathrm{na}^{1}$. In 2014, 12 of these 15 countries that regularly report data to the World Health Organization (WHO) notified 2200 new cases of BUD $^{2}$. This figure was more than $50 \%$ less than the number of cases they notified in 2009 - indicating that except for a few countries, the number of BUD cases has declined since $2010^{2}$.
C) 2019 Nwafor et al. Licensee African Health Sciences. This is an Open Access article distributed under the terms of the Creative commons Attribution License (https://creativecommons.org/licenses/BY/4.0), which permits unrestricted use, distribution, and reproduction in any medium, provided the original work is properly cited.

African Health Sciences Vol 19 Issue 2, June, 2019 
In Nigeria, BUD was first reported from Benue in 1967 in four patients ${ }^{4}$. Since then, until recently, there have been scanty reports from different States in Southern Nigeria $^{4-5}$. Recently, in 2012 a BUD prevalence of 18.7 per 100,000 population (range: 6.0 to 41.4 per 100,000) was reported in Ogoja territory, Nigeria ${ }^{6}$. So far, BUD cases have been reported from over 8 States of Nigeria viz. Adamawa, Benue, Cross River, Akwa Ibom, Enugu, Anambra, Delta, Ogun and $\mathrm{Oyo}^{4-8}$. Recent reports from Nigeria indicate that the number of new BUD cases diagnosed is increasing every year ${ }^{6-8}$. As a result, there is a growing interest in BUD in the country and case finding strategies for BUD in Nigeria are being scaled-up ${ }^{6-8}$.

BUD patients have been found to have substantial delays in seeking appropriate care thereby incurring catastrophic costs as well as acquiring secondary bacterial infections as complications ${ }^{7-8,10}$. Thus, due to late presentation, they may require extensive surgery and management of the resultant disability ${ }^{9}$. There is a paucity of research on community knowledge of BUD in endemic settings of West Africa ${ }^{11-14}$. The WHO recommends evaluation of community-level understanding of BUD in order to design culturally-appropriate and behaviourally-feasible prevention and treatment interventions ${ }^{15}$. This data is crucial in informing the need for changing policies in improving BUD control programme. Therefore, the aim of this study was to assess community knowledge, attitude and stigma of BUD in endemic communities in Southern Nigeria.

\section{Materials \& methods \\ Study design}

This was a community-based cross-sectional survey of BUD-endemic settings in Southern Nigeria between July and August 2016.

\section{Study area and population}

The study was carried out in four States (Cross River, Anambra, Delta and Ogun) in Southern Nigeria. The States belong to the tropical rain-forest belt characterised by several features including rivers and swamps. In each of the selected States two local government areas (basic management units) notifying the highest number of BUD cases where an active case finding intervention for BUD was ongoing were used as the study sites. Thus, eight local government areas consisting of Ogoja and Yala (Cross River State), Ogbaru and Anambra East (Anambra State),
Okpe and Ethiope East (Delta State) and Yewa South and Yewa North (Ogun State) having an estimated population of more than one million people constituted the study site. The study participants were heads of households or the next available adult ( $>18$ years) in a selected household in the study communities.

\section{Sampling}

Using household census data obtained from each of the selected local government area administrative headquarters, 65 households were selected through simple random sampling from each participating local government area (i.e., 130 households per State). In each selected household, the head of the household or the next available adult was interviewed.

\section{Sample size}

Sample size was calculated using OpenEpi 16. A minimum sample of 384 persons will be able to detect an estimated $50 \%$ prevalence of community members with good knowledge of BUD at 95\% confidence level and an absolute sampling error of 0.05 . In this study, we increased the sample size to 520 households to allow for attrition and further multivariable analysis.

\section{Instruments and data collection}

The study instrument was an interviewer-administered questionnaire which had been piloted and validated. This questionnaire had four sections namely: demographics; knowledge of BUD; attitude towards the BU disease sufferers; and stigma towards persons with BUD. The knowledge component consisted of 10 questions covering the awareness, aetiology, clinical presentation, transmission, treatment and prevention. The questions consisted of factual statements that participants responded to with "yes", "no" or "I don't know" options. A scoring system was applied to assess the level of knowledge of each respondent and one point was awarded for each correct answer. No point was given for an incorrect answer. In addition, participants were also asked further specific questions regarding their perceptions of the causes, transmission, treatment and prevention of BUD. Five questions each related to attitudes towards the disease, and stigma against persons suffering from the disease were also applied.

The survey instrument was reviewed by a group of aca- 
demics, infectious disease physicians, epidemiologists and public health physicians within the State Tuberculosis, Leprosy and Buruli ulcer Control Programmes of Cross River, Anambra, Delta and Ogun States who considered it to have face validity. Minor modifications were made to the initial questionnaire following their review. Pre-testing was performed among 20 adult community members in Ayamelum local government area, Anambra State not used for the survey which also led to minor changes in the initial questionnaire.

Two locally recruited research assistants with higher education and had participated in a standardised training session were recruited to administer the questionnaire in each State.

\section{Data analysis}

The data were double-entered, and analysed using Epi Info 3.4.1 (CDC, Atlanta, GA USA). A composite score for knowledge of BUD was estimated for each respondent. Respondents with a knowledge score of $\geq 70 \%$ were considered to have good knowledge and those with $<70 \%$ were considered to have poor knowledge of BUD. Continuous variables were summarised as means ( \pm standard deviation SD) and while categorical variables were summarised as proportions. Group comparisons were made using the $\chi^{2}$ test. A multivariable logistic regression analysis was performed to identify predictors of good knowledge of BUD. A p-value $<0.05$ was considered significant.

\section{Ethical approval}

The study was approved by the Ethics and Research Advisory Board of the German Leprosy and TB Relief Association, Nigeria. Approval was also obtained from the State TB, Leprosy and Buruli ulcer Control Programme in the study States. All participants gave an oral informed consent to participate in the survey.

\section{Results}

\section{Demographic characteristics of respondents}

A total of 491 respondents with complete data were included in the final analysis. The respondents consisted of $257(52.3 \%)$ male, and $315(64.2 \%)$ were aged $\leq 40$ years (Table 1). Most of the respondents were Christians $453(92.3 \%)$, married 351 (71.5\%), farmers 415 (84.5\%), and had formal education i.e., completed at least six years of schooling $416(84.7 \%)$. Only $66(13.5 \%)$ of the respondent households had a regular income source, 226 $(46.0 \%)$ had irregular income sources and 119 (40.5\%) had no defined income source (Table 1). 
Table 1: Socio-demographic characteristics of the respondents $(N=491)$

\begin{tabular}{ll}
\hline Variables & $\mathrm{n}(\%)$ \\
\hline Age group (years) & \\
$\leq 40$ & $315(64.2)$ \\
$>40$ & $176(35.8)$ \\
Gender & \\
$\quad$ Female & $234(47.7)$ \\
Male & $257(52.3)$ \\
Educational status & \\
$\quad$ No formal education & $75(15.3)$ \\
Primary & $153(31.2)$ \\
Secondary & $211(43.0)$ \\
Tertiary & $52(10.6)$ \\
Marital status & \\
Single & $118(24.0)$ \\
Married & $351(71.5)$ \\
Widowed & $22(4.5)$ \\
Ethnic group & \\
$\quad$ Igbo & \\
Other & $128(26.1)$ \\
Yoruba & $250(50.9)$ \\
Religion & $113(23.0)$ \\
Christianity & \\
Islam & \\
Traditional religion & $453(92.3)$ \\
Occupation & $18(3.7)$ \\
Civil service & $20(4.1)$ \\
Farmer & \\
Other & \\
Monthly household income sources & $44(9.0)$ \\
Irregular & $415(84.5)$ \\
No defined income & $32(6.5)$ \\
Regular income & \\
\hline
\end{tabular}

\section{Knowledge of Buruli ulcer disease}

The respondents were assessed regarding their knowledge of BUD (Table 2). The overall mean (SD) knowledge score was $5.5 \pm 2.3$ (maximum 10) suggesting that they generally had a fair knowledge of BUD (Table 2). However, the most knowledge deficit was in identifying a key risk factor of BUD: only $152(31.0 \%)$ of the respondents could identify one key risk factor of BUD. Other major knowledge deficits were: only 240 (48.9\%) knew that BUD cannot be transmitted through contact with infected persons, only $271(55.2 \%)$ of the respondents knew that BUD can be prevented and only 167 (34.0\%) identified at least one correct preventive measure against
BUD (Table 2). Older individuals (>40years) tended to have better awareness of BUD compared with younger respondents $(86.9 \%$ vs. $77.5 \% ; \mathrm{p}=0.01)$. However, they were less likely to identify a key risk factor of BUD (24.4\% vs. $34.6 \% ; \mathrm{p}=0.02)$, less likely to know that BUD can be prevented $(50.6 \%$ vs. $57.8 \% ; \mathrm{p}=0.017)$, less likely to identify one correct preventive measure against BUD (25\% vs. 39.1\%; $\mathrm{p}=0.002)$. Overall, only $172(35.0 \%$; $95 \%$ C.I. 30.8 to $39.5 \%$ ) of the respondents had a good knowledge of BUD (Table 3). The proportion of respondents with good knowledge of BUD varied across the study States: 46.2\% (60/130) in Cross River, 30.2\% (38/126) in Anambra, 22.3\% (27/121) in Delta, and 41.2\% (47/114) in Ogun State $(\mathrm{P}<0.001)$. 
Table 2: Respondents knowledge of Buruli ulcer disease according to their age groups

\begin{tabular}{lllll}
\hline Variable & $\begin{array}{l}\mathrm{n}(\%) \text { correct } \\
\text { Total }\end{array}$ & $\begin{array}{l}\mathrm{n}(\%) \text { correct } \\
(\leq 40 \text { years })\end{array}$ & $\begin{array}{l}\mathrm{n}(\%) \text { correct } \\
(>40 \text { years })\end{array}$ & P-value \\
\hline Overall & 491 & 315 & 176 & \\
$\begin{array}{l}\text { Ever heard about the Buruli ulcer } \\
\text { disease }\end{array}$ & $397(80.9)$ & $244(77.5)$ & $153(86.9)$ & 0.01 \\
$\begin{array}{l}\text { Had an information source of Buruli } \\
\text { ulcer disease }(\mathrm{N}=397)\end{array}$ & $397(100)$ & $244(100)$ & $153(100)$ & 0.99 \\
$\begin{array}{l}\text { Identified a key risk factor of Buruli } \\
\text { ulcer disease }\end{array}$ & $152(31.0)$ & $109(34.6)$ & $43(24.4)$ & 0.02 \\
$\begin{array}{l}\text { Identified two or more clinical } \\
\text { presentation of Buruli ulcer disease }\end{array}$ & $378(77.0)$ & $237(75.2)$ & $141(80.1)$ & 0.22 \\
$\begin{array}{l}\text { Knew that Buruli ulcer cannot be } \\
\text { transmitted through contact with }\end{array}$ & $240(48.9)$ & $146(46.3)$ & $94(53.4)$ & 0.20 \\
$\begin{array}{l}\text { infected persons } \\
\begin{array}{l}\text { Knew that Buruli ulcer disease } \\
\text { cannot be transmitted through }\end{array}\end{array}$ & $454(92.5)$ & $291(92.4)$ & $163(92.6)$ & 0.92 \\
$\begin{array}{l}\text { formites } \\
\text { Knew that Buruli ucer disease can } \\
\text { be prevented }\end{array}$ & $271(55.2)$ & $182(57.8)$ & $89(50.6)$ & 0.017 \\
$\begin{array}{l}\text { Identified at least one correct } \\
\text { preventative method against Buruli } \\
\text { ulcer }\end{array}$ & $167(34.0)$ & $123(39.1)$ & $44(25.0)$ & 0.002 \\
$\begin{array}{l}\text { Knew that Buruli ulcer disease } \\
\text { could be cured }\end{array}$ & $409(83.3)$ & $257(81.6)$ & $152(86.4)$ & 0.39 \\
$\begin{array}{l}\text { Identified that Buruli ulcer disease } \\
\text { could be cured though modern } \\
\text { medications and surgery }\end{array}$ & $332(67.6)$ & $211(67.0)$ & $121(68.8)$ & 0.69 \\
\hline
\end{tabular}

Table 3: Proportions of respondents' knowledge of Buruli ulcer according to their age group

\begin{tabular}{llll}
\hline Variable & $\begin{array}{l}\text { Total } \\
\mathrm{n}(\% ; 95 \% \mathrm{Cl})\end{array}$ & $\begin{array}{l}\leq 40 \text { years } \\
\mathrm{n}(\% ; 95 \% \mathrm{Cl})\end{array}$ & $\begin{array}{l}>40 \text { years } \\
\mathrm{n}(\% ; 95 \% \mathrm{Cl})\end{array}$ \\
\hline Overall & 491 & 315 & 176 \\
& & & \\
\% of & & & \\
knowledge & & & \\
score & & & $45(25.6 ; 19.3-32.7)$ \\
$\quad \leq 49$ & $132(26.9 ; 23.1-31.1)$ & $87(27.6 ; 22.8-33.0)$ & $41(23.3 ; 17.3-30.2)$ \\
$50-59$ & $112(22.8 ; 19.2-26.8)$ & $71(22.5 ; 18.1-27.6)$ & $28(15.9 ; 10.8-22.2)$ \\
$\quad 60-69$ & $75(15.3 ; 12.3-18.8)$ & $47(14.9 ; 11.3-19.5)$ & \\
$\quad \geq 70$ & $172(35.0 ; 30.8-39.5)$ & $110(34.9 ; 29.7-40.5)$ & $62(35.2 ; 28.2-42.8)$ \\
& & & \\
Knowledge & & & \\
level & & & \\
$\quad$ Good & $172(35.0 ; 30.8-39.5)$ & $110(34.9 ; 29.7-40.5)$ & $62(35.2 ; 28.2-42.8)$ \\
$\quad$ Poor & $319(65.0 ; 60.5-69.2)$ & $205(65.1 ; 59.5-70.3)$ & $114(64.8 ; 57.2-71.8)$ \\
\hline
\end{tabular}

Some $221(45.0 \%)$ of the respondents indicated that they did not know the aetiology of BUD, 102 (20.8\%) perceived that the disease was caused by an infective organism, $105(21.4 \%)$ perceived it to be caused by witchcraft, $95(19.3 \%)$ perceived the disease to be caused by contact with swamps, and $63(12.8 \%)$ perceived it was caused by swimming in rivers/streams (Figure 1). Furthermore, the majority $372(75.8 \%)$ of the respondents indicated that they did not know the mode of transmission of BUD. However, a few of the respondents believed it could be transmitted through aerosol 36 (7.3\%); while others believed it could be transmitted through fomites in public places 37 (7.5\%); sharing of cups for drinking water 24 $(4.9 \%)$, or eating from the same plates with affected persons $20(4.1 \%)$. In addition, the respondents had a varied perception on the preventability of BUD (Figure 1). 
Some of the respondents perceived that the disease could be prevented by: avoiding swimming in rivers and streams $89(18.1 \%)$, wearing protective clothing in swamps 78 $(15.9 \%)$, or drinking clean/portable water $68(13.8 \%)$.
Furthermore, $332(67.6 \%)$ of the respondents perceived that BUD can be cured using modern medications and surgery, $173(35.2 \%)$ perceived it could be cured by herbal remedies only, and $69(14.1 \%)$ perceived it could be cured through prayers (Figure 1)
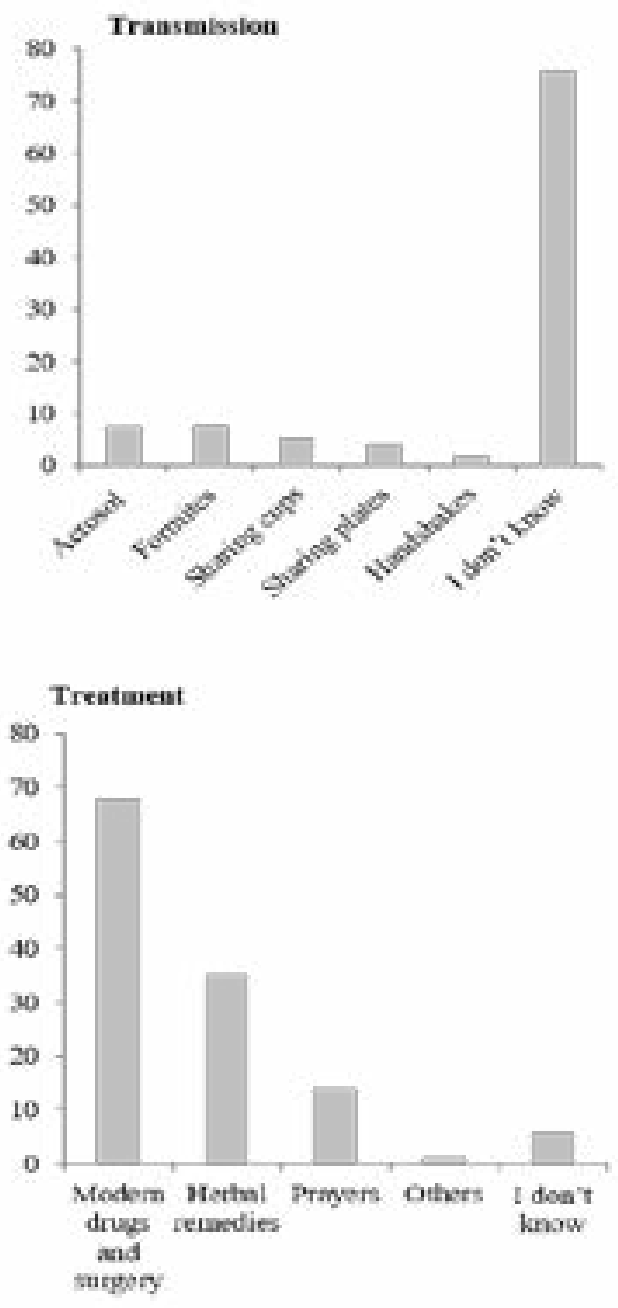

Figure 1: Respondents knowledge of the aetiology, transmission, treatment and prevention of Buruli ulcer in Southern Nigeria

\section{Attitudes to Buruli ulcer disease}

A total of $327(66.6 \%)$ and $55(11.2 \%)$ considered BUD as a very serious or a somewhat serious illness, respectively (Table 4). Also, 189 (38.5\%) and 72 (14.7\%) considered BUD to be a very serious or a somewhat serious illness in their community, respectively. The respondents' attitude to being diagnosed with BUD mainly includes; fear $120(24.4 \%)$, sadness or hopelessness 116 (23.6\%), surprise $112(22.8 \%)$ and shame 50 (10.2\%). Although only $130(26.5 \%)$ of the respondents had a positive attitude towards the curability of BUD, most indicated that their first source of advice/help following being diagnosed with the disease is a healthcare worker, 257 $(52.3 \%)$, others indicated that they would seek help from their spouse $74(15.1 \%)$, parents $55(11.2 \%)$ or a close friend $25(5.1 \%)$. 
Table 4: Attitude to Buruli ulcer disease among the study respondents $(N=491)$

\begin{tabular}{|c|c|}
\hline Variable & n (\%) \\
\hline \multicolumn{2}{|c|}{ Attitude to seriousness of Buruli ulcer disease as an illness } \\
\hline Very serious & $327(66.6)$ \\
\hline Somewhat serious & $55(11.2)$ \\
\hline Not very serious & $60(12.2)$ \\
\hline Don't know & $49(10.0)$ \\
\hline \multicolumn{2}{|c|}{ Attitude to seriousness of Buruli ulcer disease in respondent's community } \\
\hline Very serious & $189(38.5)$ \\
\hline Somewhat serious & $72(14.7)$ \\
\hline Not very serious & $165(33.6)$ \\
\hline Don't know & $65(13.2)$ \\
\hline \multicolumn{2}{|c|}{ Attitude to the curability of Buruli ulcer disease } \\
\hline Yes & $130(26.5)$ \\
\hline No & $283(57.6)$ \\
\hline Don't know & $78(15.9)$ \\
\hline \multicolumn{2}{|c|}{ Respondent's reaction to being diagnosed with Buruli ulcer disease } \\
\hline Fear & $120(24.4)$ \\
\hline Surprise & $112(22.8)$ \\
\hline Shame & $50(10.2)$ \\
\hline Sadness or hopelessness & $116(23.6)$ \\
\hline Others & $93(18.9)$ \\
\hline \multicolumn{2}{|c|}{$\begin{array}{l}\text { Respondents' first source of advice/help following being diagnosed with Buruli ulcer } \\
\text { disease }\end{array}$} \\
\hline Healthcare worker / doctor & $257(52.3)$ \\
\hline Spouse & $74(15.1)$ \\
\hline Parent & $55(11.2)$ \\
\hline Close friend & $25(5.1)$ \\
\hline No one & 19 (3.9) \\
\hline Others & $61(12.4)$ \\
\hline
\end{tabular}

Community stigma towards persons with Buruli ulcer disease

A total of $344(70.1 \%)$ of the respondents knew a person who have or have had BUD in their community (Table 5). Also, respondents were asked what they felt for persons with BUD (Table 5): 372 (75.8\%) felt compassion and desire to help them, 77 (15.7\%) felt compassion but tended to stay away from them, $53(10.8 \%)$ feared them because they may infect them with the disease, and 30 $(6.1 \%)$ indicated that they have no particular feelings towards them. The respondents were further asked how persons with BUD are treated in their community: 277
$(56.4 \%)$ of them indicated that they are allowed to freely interact with persons with the disease, 388 (79.0\%) indicated that they don't allow their children to freely interact with persons with the disease, $403(82.1 \%)$ reported that they don't allow persons with BUD to work as teachers in the community, and $385(78.4 \%)$ indicated that they do not welcome persons with BUD into their homes. Only $202(41.1 \%)$ of the respondents perceived that some individuals are more likely to develop BUD than others. However, when asked to identify such individuals, their answers ranged from men only $31(6.3 \%)$ or women only $31(6.3 \%)$, to children $107(21.8 \%)$, and only adults 150 (30.5\%). 
Table 5: Community perceptions and stigma towards persons with Buruli ulcer disease $(\mathrm{N}=491)$

\begin{tabular}{|c|c|}
\hline Variable & $\mathrm{n}(\%)$ \\
\hline \multicolumn{2}{|l|}{ Knew a person/persons who have or have had Buruli ulcer disease } \\
\hline Yes & $344(70.1)$ \\
\hline No & $114(23.2)$ \\
\hline Don't know & $33(66.7)$ \\
\hline \multicolumn{2}{|l|}{ What the respondents feels for persons with Buruli ulcer disease } \\
\hline Feels compassion and desire to help & $372(75.8)$ \\
\hline Feels compassion but tended to stay away from them & $77(15.7)$ \\
\hline Fears them because they may infect him/her & $53(10.8)$ \\
\hline Have no particular feelings towards them & $30(6.1)$ \\
\hline Others & $40(8.1)$ \\
\hline \multicolumn{2}{|l|}{ How persons with Buruli ulcer disease are treated in the community } \\
\hline We are allowed to freely interact with persons with Buruli ulcer & $277(56.4)$ \\
\hline We don't allow our children freely interact with a Buruli ulcer patient & $388(79.0)$ \\
\hline We don't allow persons with Buruli ulcer to work as teachers in the community & $403(82.1)$ \\
\hline $\begin{array}{l}\text { We don't We don't allow persons with Buruli ulcer to work as teachers in the } \\
\text { community }\end{array}$ & $385(78.4)$ \\
\hline Most people are friendly to them, but they generally try to avoid him or her & $90(18.3)$ \\
\hline The community mostly do not support and/or help them & $355(72.3)$ \\
\hline Other & \\
\hline \multicolumn{2}{|l|}{$\begin{array}{l}\text { Respondents perception on some persons being more likely to develop Buruli } \\
\text { ulcer disease than others }\end{array}$} \\
\hline Yes & $202(41.1)$ \\
\hline No & $185(37.7)$ \\
\hline Not sure & $104(21.2)$ \\
\hline \multicolumn{2}{|l|}{ In your opinion, which persons are more likely to develop Buruli ulcer disease } \\
\hline Men & $31(6.3)$ \\
\hline Women & $31(6.3)$ \\
\hline Adult male and females & $150(30.5)$ \\
\hline Children & $107(21.8)$ \\
\hline Others & $42(8.6)$ \\
\hline I don't know & $81(16.5)$ \\
\hline
\end{tabular}

Factors associated with knowledge of Buruli ulcer disease

The relationship between the socio-demographic characteristics of the respondents and knowledge of BUD are as shown in (Supplementary Tables S1, and S2; Appendix 1). Good knowledge of BUD did not differ according to age $(p=0.95)$ or gender $(p=0.70)$ categories. Also, good knowledge of BUD did not differ according to marital status $(p=0.56)$, religion $(p=0.61)$, occupation $(p=$ $0.16)$ or household income sources $(p=0.09)$. However, respondents with a formal education were more likely to have good knowledge of BUD compared to those with no formal education $(p=0.009)$, and respondents who are from the Igbo and Yoruba ethnic groups were more likely to have good knowledge of BUD compared to those from "other" ethnic groups $(p=0.004)$. Bivariate and multivariable logistic regression analysis was performed to determine socio-demographic predictors of good knowledge of BUD among the respondents (Table S2). The independent predictors for good knowledge of BUD among the respondents were: completing a primary adjusted odds ratio (aOR) 2.2, 95\% CI $1.04-5.5$ or secondary (aOR 3.0, 95\% CI $1.4-6.1$ ) or a tertiary education (aOR 4.5, 95\% CI 1.9 - 10.5). Further more, belonging to the "other ethnic group" was an independent predictor of lower knowledge of BUD (aOR 0.6, 95\% CI $0.4-0.9)$. 
Table S1: Relationship between respondents profile and knowledge of Buruli ulcer disease in Nigeria

\begin{tabular}{|c|c|c|c|c|}
\hline Variables & $\begin{array}{l}\text { Poor knowledge } \\
\text { n (\%) }\end{array}$ & $\begin{array}{l}\text { Good knowledge } \\
\text { n (\%) }\end{array}$ & Chi-square & P-value \\
\hline $\begin{array}{c}\text { Age (years) } \\
\leq 40 \\
>40\end{array}$ & $\begin{array}{l}205(65.1) \\
114(64.8)\end{array}$ & $\begin{array}{l}110(34.9) \\
62(35.2)\end{array}$ & 0.005 & 0.95 \\
\hline $\begin{array}{c}\text { Gender } \\
\text { Female } \\
\text { Male }\end{array}$ & $\begin{array}{l}150(64.1) \\
169(65.8)\end{array}$ & $\begin{array}{l}84(35.9) \\
88(34.2)\end{array}$ & 0.15 & 0.70 \\
\hline $\begin{array}{l}\text { Educational status } \\
\text { No formal education } \\
\text { Primary } \\
\text { Secondary } \\
\text { Tertiary }\end{array}$ & $\begin{array}{l}59(78.7) \\
97(63.4) \\
137(64.9) \\
26(50.0)\end{array}$ & $\begin{array}{l}16(21.3) \\
56(36.6) \\
74(35.1) \\
26(50.0)\end{array}$ & 11.5 & 0.009 \\
\hline $\begin{array}{l}\text { Marital status } \\
\text { Single } \\
\text { Married } \\
\text { Widowed }\end{array}$ & $\begin{array}{l}81(68.6) \\
225(64.1) \\
13(59.1)\end{array}$ & $\begin{array}{l}37(31.4) \\
126(35.9) \\
9(40.9)\end{array}$ & 1.1 & 0.56 \\
\hline $\begin{array}{l}\text { Ethnic group } \\
\text { Igbo } \\
\text { Other } \\
\text { Yoruba }\end{array}$ & $\begin{array}{l}75(58.6) \\
180(72.0) \\
64(56.6)\end{array}$ & $\begin{array}{l}53(41.4) \\
70(28.0) \\
49(43.4)\end{array}$ & 11.2 & 0.004 \\
\hline $\begin{array}{l}\text { Religion } \\
\text { Christianity } \\
\text { Islam } \\
\text { Traditional religion }\end{array}$ & $\begin{array}{l}297(65.6) \\
10(55.6) \\
12(60.0)\end{array}$ & $\begin{array}{l}156(34.4) \\
8(44.4) \\
8(40.0)\end{array}$ & 0.99 & 0.61 \\
\hline $\begin{array}{l}\text { Occupation } \\
\text { Civil service } \\
\text { Farmer } \\
\text { Other }\end{array}$ & $\begin{array}{l}23(52.3) \\
276(66.5) \\
20(62.5)\end{array}$ & $\begin{array}{l}21(47.7) \\
139(33.5) \\
12(37.5)\end{array}$ & 3.6 & 0.16 \\
\hline $\begin{array}{l}\text { Income sources } \\
\text { Irregular } \\
\text { No defined source } \\
\text { Regular } \\
\end{array}$ & $\begin{array}{l}150(66.4) \\
134(67.3) \\
35(53.0)\end{array}$ & $\begin{array}{l}76(33.6) \\
65(32.7) \\
31(47.0) \\
\end{array}$ & 4.8 & 0.09 \\
\hline
\end{tabular}


Table S2: Logistic regression analysis of factors associated with good knowledge

of Buruli ulcer disease in Nigeria

\begin{tabular}{|c|c|c|c|c|}
\hline Variables & $\begin{array}{l}\text { Good knowledge } \\
\mathrm{n}(\%)\end{array}$ & $\begin{array}{l}\text { Crude OR } \\
(95 \% \mathrm{Cl})\end{array}$ & $\begin{array}{l}\text { Adjusted OR } \\
(95 \% \mathrm{Cl})\end{array}$ & $\begin{array}{l}\text { Adjusted } \\
\text { P-value }\end{array}$ \\
\hline \multicolumn{5}{|l|}{ Age (years) } \\
\hline$\leq 40$ & $110(34.9)$ & 1 & 1 & \\
\hline$>40$ & $62(35.2)$ & $1.01(0.7-1.5)$ & $1.2(0.7-1.8)$ & 0.55 \\
\hline \multicolumn{5}{|l|}{ Gender } \\
\hline Female & $84(35.9)$ & $1.1(0.7-1.6)$ & $1.1(0.7-1.6)$ & 0.79 \\
\hline Male & $88(34.2)$ & 1 & 1 & \\
\hline \multicolumn{5}{|l|}{ Educational status } \\
\hline No formal education & $16(21.3)$ & 1 & 1 & \\
\hline Primary & $56(36.6)$ & $2.2(1.2-4.2)$ & $2.7(1.4-5.5)$ & 0.005 \\
\hline Secondary & $74(35.1)$ & $2.0(1.1-3.7)$ & $3.0(1.4-6.1)$ & 0.004 \\
\hline Tertiary & $26(50.0)$ & $3.4(1.6-7.4)$ & $4.5(1.9-10.5)$ & $<0.001$ \\
\hline \multicolumn{5}{|l|}{ Marital status } \\
\hline Single & $37(31.4)$ & $0.8(0.5-1.3)$ & $0.8(0.5-1.4)$ & 0.44 \\
\hline Married & $126(35.9)$ & 1 & 1 & \\
\hline Widowed & $9(40.9)$ & $1.2(0.5-3.0)$ & $2.6(0.9-7.0)$ & 0.07 \\
\hline \multicolumn{5}{|l|}{ Ethnic group } \\
\hline Igbo & $53(41.4)$ & 1 & 1 & \\
\hline Other & $70(28.0)$ & $0.6(0.4-0.9)$ & $0.6(0.4-0.9)$ & 0.02 \\
\hline Yoruba & $49(43.4)$ & $1.1(0.7-1.8)$ & $1.4(0.8-2.4)$ & 0.27 \\
\hline \multicolumn{5}{|l|}{ Income sources } \\
\hline Irregular & $76(33.6)$ & 1 & 1 & \\
\hline No defined source & $65(32.7)$ & $1.02(0.7-1.5)$ & $1.1(0.7-1.6)$ & 0.76 \\
\hline Regular & $31(47.0)$ & $1.7(1.0-2.9)$ & $1.6(0.7-1.6)$ & 0.10 \\
\hline
\end{tabular}

$\mathrm{OR}$; odds ratio, $95 \% \mathrm{Cl}=95 \%$ confidence interval

\section{Discussion}

This study has shown that majority of individuals living in endemic settings in Nigeria had poor knowledge of BUD. Only about a fifth of them knew that the disease is caused by an infective organism; and similar proportions reported that it may be caused by contact with swamps or witchcraft. Our finding was consistent with reports from Cameroon and Ghana which showed a high variation in community knowledge of the aetiology of BUD with a substantial proportion attributing the disease to witchcraft $^{11-14}$. This wrong knowledge of the cause of BUD led affected persons to consult traditional medical practitioners and faith healers for help ${ }^{7,9,11}$. Although majority of the respondents indicated not knowing the mode of transmission of BUD, only very few $(<10 \%$ each) inappropriately perceived that the disease could be transmitted through fomites, aerosol droplet, handshake or sharing of household items like cups and plates. It is crucial that in undertaking further health education programme in populations with BUD there is a need to highlight that there is no evidence of BUD transmission through these means.

Furthermore, less than one-sixth of the respondents correctly knew that wearing of protective clothing and avoiding swimming in rivers and swamps could help in the prevention of BUD. Some of the respondents inap- propriately perceived that wearing a mask to cover their nose and mouth as well as drinking potable water could prevent BUD. Thus, despite a high awareness of BU in the community, respondents generally showed a poor knowledge of its prevention. In addition, we observed some variation in the proportion of respondents with good knowledge of BUD in the study States which followed the pattern of the integration of the States with the BUD Control Programme. Some of the observations in this study disagree with those of Akoachere et al., ${ }^{14}$ in Cameroun who found that almost half $(49.4 \%)$ of their respondents thought that BUD could be transmitted from one person to another.

Also, we found that a relatively high proportion of the respondents believed in the preventability of BUD. This suggests that the ongoing sensitisation and outreach programmes in BUD-endemic settings of Southern Nigeria may have contributed to an improved knowledge of the preventability of the disease. This is unlike a similar study in Cameroon which found that more than half of the respondents believed BUD cannot be prevented suggesting that the community sensitization on BUD in the study area is insufficient and needs to be reinforced ${ }^{14}$. Some of the preventive measures mentioned by the respondents who perceived BUD to be preventable in this study have been reported in previous studies ${ }^{17-19}$. 
This study revealed some positive attitudes towards BUD with the majority of respondents perceiving the illness to be a serious problem in their communities. Only few of the respondents had a positive attitude towards the curability of the disease. As a result, the majority of respondents will react to a diagnosis of BUD by being afraid, ashamed, surprised or depressed. However, majority of them indicated a positive attitude towards appropriate care-seeking by identifying a health worker / doctor as their choice for advice if they develop BUD.

Although majority of the respondents indicated a willingness to help BUD sufferers, we found a high level of social stigma towards persons with BUD. This is consistent with other published studies which reported on stigma and discrimination faced by patients with BUD ${ }^{11,20,21}$. This high level of social stigma e.g., not allowing persons with BUD to work as teachers, suggests that the stigma demonstrated may be due to fear of contacting the disease ${ }^{11,21}$. However, in Ghana there was a high level of acceptance of BUD-affected persons with persistent community education and exposure to these persons. Stienstra et al., ${ }^{11}$ hypothesised that there may be a link between reduced stigma and burden of BUD in a given area i.e., a greater level of acceptance of BUD because of familiarity with the disease in an area leads to increased case detection and high prevalence rates.

Only educational status and ethnicity were found to be independent predictors of good knowledge of BUD. We found that all levels of formal education were predictors of good knowledge of BUD. Improved education of community members could contribute to easy dissemination of information. The role of education in improved community knowledge of BUD has been shown by studies in Ghana and Cameroun ${ }^{12,14,22}$. Education remains a key instrument in driving social change and helps in changing ones perception about a disease e.g., acceptance of BUD patients by community members. We also found that ethnicity was an independent predictor of knowledge of BUD with patients belonging to the "other" smaller ethnic groups (besides the major Igbo and Yoruba ethnic groups) in the study setting had poorer knowledge of BUD. These communities and the health care workers serving them will benefit from further targeted educational programmes in order to improve their knowledge of the disease $\mathrm{e}^{23}$.
This study has some strengths and limitations. A key strength of this study was it was carriedout in communities in Nigeria where little or no literature is available. In addition, it was performed in four States with the highest burden of BUD in Nigeria. Therefore, the findings of this study can help stakeholders and other health policymakers to plan culturally-appropriate and behaviourally-feasible community education and prevention interventions against BUD in the country. However, as this was a descriptive cross-sectional study we cannot make any causal inferences. Moreover, there may be other confounders and predictors of knowledge of BUD not explored. A qualitative study would strengthen the findings of this study and improve upon these limitations.

\section{Conclusion}

We found that there is poor knowledge of BUD in endemic settings of Nigeria which influenced the attitude of community members and increased stigma towards persons with BUD. We recommend that the National Tuberculosis, Leprosy and Buruli Ulcer Control Programme of Nigeria should strengthen community education programmes on the presentation, known risk factors of the disease and its preventive measures in order to improve community attitudes and reduce stigma towards persons with BUD. Further emphasis of such educational programmes should be on early recognition of symptoms of BUD and prompt referral for appropriate care.

\section{Conflict of interest}

None declared.

\section{References}

1. Sizaire V, Nackers F, Comte E, Portaels F. Mycobacterium ulcerans infection: control, diagnosis, and treatment. Lancet Infect Dis. 2006; 6 (5): 288-296.

2. WHO. Buruli ulcer disease factsheet. Geneva: World Health Organization; 2017. http://www.who.int/mediacentre/factsheets/fs199/en/

3. Wansbrough-Jones M, Phillips R. Buruli ulcer: emerging from obscurity. Lancet 2006; 367(9525): 1849-1858.

4. Gray HH, Kingma S, Kok SH. Mycobacterial skin ulcers in Nigeria. Trans R Soc Trop Med Hyg. 1967; 61 (5): 712-714.

5. Oluwasanmi JO, Solankee TF, Olurin EO, Itayemi SO, Alabi GO, Lucas AO. Mycobacterium ulcerans (Buruli) skin ulceration in Nigeria. Am J Trop Med Hyg. 1976; 25(1): 122-128. 
6. Ukwaja KN, Meka AO, Chukwuka A, Asiedu KB, Huber KL, Eddyani M, et al. Buruli ulcer in Nigeria: Results of a pilot case study in three rural districts. Infect Dis Poverty. 2016;5:39

7. Meka AO, Chukwu JN, Nwafor CC, Oshi DC, Madichie NO, Ekeke N, et al. Diagnosis delay and duration of hospitalisation of patients with Buruli ulcer in Nigeria. Trans R Soc Trop Med Hyg. 2016; 110 (9): 502-509

8. Chukwu JN, Meka AO, Nwafor CC, Oshi DC, Madichie NO, Ekeke N, et al. Financial burden of health care for Buruli ulcer patients in Nigeria: the patients' perspective. Int Health. 2017; 9 (1): 36-43.

9. Huang GKL, Johnson PD. Epidemiology and management of Buruli ulcer. Expert Rev Anti Infect Ther. 2014; 12(7): 855-865.

10. Anyim MC, Meka AO, Chukwu JN, Nwafor CC, Oshi DC, Madichie NO, et al. Secondary bacterial isolates from previously untreated Buruli ulcer lesions and their antibiotic susceptibility patterns in Southern Nigeria. Rev Soc Bras Med Trop. 2016; 49 (6): 746-751

11. Stienstra Y, van der Graaf WT, Asamoa K, van der Werf TS. Beliefs and attitudes toward Buruli ulcer in Ghana. Am J Trop Med Hyg. 2002; 67 (2): 207-213.

12. Renzaho AM, Woods PV, Ackumey MM, Harvey SK, Kotin J. Community-based study on knowledge, attitude and practice on the mode of transmission, prevention and treatment of the Buruli ulcer in Ga West District, Ghana. Trop Med Int Health. 2007; 12 (3): 445-458.

13. Kamga LF, Nsagha DS, Assob JCN, Njunda AL, Ndefon P, Palle JN, Ngowe NM et al. Buruli ulcer in Cameroon: an assessment of the community knowledge pattern. African Journal of Integrated Health. 2013; 02:36-39 14. Akoachere JF, Nsai FS, Ndip RN. A Community Based Study on the Mode of Transmission, Prevention and Treatment of Buruli Ulcers in Southwest Cameroon: Knowledge, Attitude and Practices. PLoS One. 2016;11(5) :e0156463.
15. World Health Organization. Report of the 5th WHO Advisory Group Meeting on Buruli Ulcer: March 11-14 2002. Geneva, Switzerland 2003.

16. Dean AG, Sullivan KM, Soe MM. OpenEpi: Open Source Epidemiologic Statistics for Public Health, Version. www.OpenEpi.com, updated 2014/09/22. (accessed 2016/05/24).

17. Raghunathan PL, Whitney EA, Asamoa K, Stienstra Y, Taylor TH Jr, Amofah GK, et al. Risk factors for Buruli ulcer disease (Mycobacterium ulcerans infection): results from a case-control study in Ghana. Clin Infect Dis. 2005; 40 (10):1445-1453.

18. Pouillot R, Matias G, Wondje CM, Portaels F, Valin N, Ngos F, et al. Risk factors for Buruli ulcer: a case control study in Cameroon. PLoS Negl Trop Dis. 2007; 1(3) :e101. 19. Kenu E, Nyarko KM, Seefeld L, Ganu V, Käser M, Lartey M, et al. Risk factors for Buruli ulcer in Ghana-a case control study in the Suhum-Kraboa-Coaltar and Akuapem South Districts of the Eastern region. PLoS Negl Trop Dis. 2014; 8(11) :e3279.

20. Tawiah PE, Adongo PB, Aikins M. Mental Health-Related Stigma and Discrimination in Ghana: Experience of Patients and Their Caregivers. Ghana Med J. 2015; 49(1):30-6.

21. Ocaya A, Kironde F, Odongo-Aginya FI. Knowledge and attitude towards Buruli ulcer disease in Adjumani district, Northwestern Uganda. East Afr Med J. 2005; 92 (11): 537-541.

22. Owusu-Sekyere E, Kwame OA, Nkuah JK. Perceptions and attitudes: the challenge of managing Buruli ulcer morbidity in Ghana. Int J Sci. 2013; 2(3):16-24

23. Ekeke N, Meka AO, Chukwu JN, Nwafor NC, Alphonsus $\mathrm{C}, \mathrm{Mbah} \mathrm{OK}$, et al. Assessment of health care workers' knowledge, attitude and risk perception of $\mathrm{Bu}-$ ruli ulcer disease in Southern Nigeria. Trans $\mathrm{R}$ Soc Trop Med Hyg. 2017; 111(5):226-232 